\title{
A STUDY ON THE IMPROVEMENT OF CADASTRAL SYSTEM IN MONGOLIA -FOCUSED ON NATIONAL LAND INFORMATION SYSTEM-
}

\author{
B. Munkhbaatar a ${ }^{\text {J }}$. Lee ${ }^{\text {a } *}$ \\ ${ }^{a}$ Dept. of Geoinfomatics, The University of Seoul, 163 Seoulsiripdaero, Seoul, South Korea - (munkh, jlee)@uos.ac.kr
}

Geomatic and Geospatial Technology

KEY WORDS: Cadastre, Cadastral System, Land Tenure, NLIS, Mongolia

\begin{abstract}
:
National land information system (NLIS) is an essential part of the Mongolian land reform. NLIS is a web based and centralized system which covers administration of cadastral database all over the country among land departments. Current ongoing NLIS implementation is vital to improve the cadastral system in Mongolia. This study is intended to define existing problems in current Mongolian cadastral system and propose administrative institutional and systematic implementation through NLIS. Once NLIS launches with proposed model of comprehensive cadastral system it will lead to not only economic and sustainable development but also contribute to citizens' satisfaction and lessen the burdensomeness of bureaucracy. Moreover, prevention of land conflicts, especially in metropolitan area as well as gathering land tax and fees. Furthermore after establishment of NLIS, it is advisable that connecting NLIS to other relevant state administrational organizations or institutions that have relevant database system. Connections with other relevant organizations will facilitate not only smooth and productive workflow but also offer reliable and more valuable information by its systemic integration with NLIS.
\end{abstract}

\section{INTRODUCTION}

In the last couple of decades, Mongolian land administration has been revitalized and intensified since 2002. This phenomenon is relevant to the establishment of cadastral legal framework. Particularly, a land law of Mongolia was approved in 1995, land privatization law of Mongolia was approved in 2002 (last amended in 2011), and as a result of land privatizing the different forms of land tenure, i.e. land ownership, land possession and land use rights have been created. According to the law, any individuals who have Mongolian citizenship are allowed to have land ownership. The government carried out free cadastral survey for privatized lands for free in 2005 (Enkhzul, 2010).

After the land privatization law of Mongolia took effect, there have been some projects implemented. One of those was the "Cadastral survey and land registration" project (ADB, 2012). The main goal of this project was a cadastral survey for: all cities, towns, villages (about 0.4 million hectares), cropland areas (about 1 million hectares), and the establishment of the National Land Information System in Mongolia. The results of the project was ending up with attribute data of the parcels of land owners, possessors and users. This included cadastral maps showing location, size, shape of the parcel, cadastral information system of Ulaanbaatar. As a second phase of the project, the National Land Information System (NLIS) was to be developed.

NLIS proposes to contribute not only for the developments of cadastral system in Mongolia but also for sustainable economic development through its comprehensive functionality.

The purpose of this study is to define existing problems in current
Mongolian cadastral system and make a proposal on the implementation. For the implementation, institutional and systematic development ways have been proposed.

The whole research is based on qualitative approach and data has been collected from primary and secondary sources. For primary data collection personal observation in the relevant organizations were conducted and for secondary sources existing literature review was done.

\section{NATIONAL LAND INFORMATION SYSTEM IN MONGOLIA}

NLIS is a web based and centralized system which covers administration of cadastral database all over the country among land departments. Administration of Land Affairs, Geodesy and Cartography, which is the government agency of Mongolia (Figure 1), decided to establish the NLIS project in 2011 and started to build in 2012. Currently NLIS is being implemented but not yet in service (Figure 2). NLIS database will be developed in an open GIS environment so that any utilities or other land - related agencies can interchange information through NLIS network (Saandar, 2003). Once it kicks off it will bring a big change in the cadastral system and be an advancement by one stage for the development. However, NLIS has some delays regarding to basic cadastral data such as unsatisfactory process of cadastral surveying and mapping, inadequate registration of land owners, users and possessors and existing cadastral law problems which does not include complex procedure for property registration, etc. In terms of cadastral data

\footnotetext{
* Corresponding author
} 
quality, it is often influenced by uncooperativeness of people and irresponsibility of surveyors, mappers, registration officers etc. NLIS is an essential part of the Mongolian land reform.

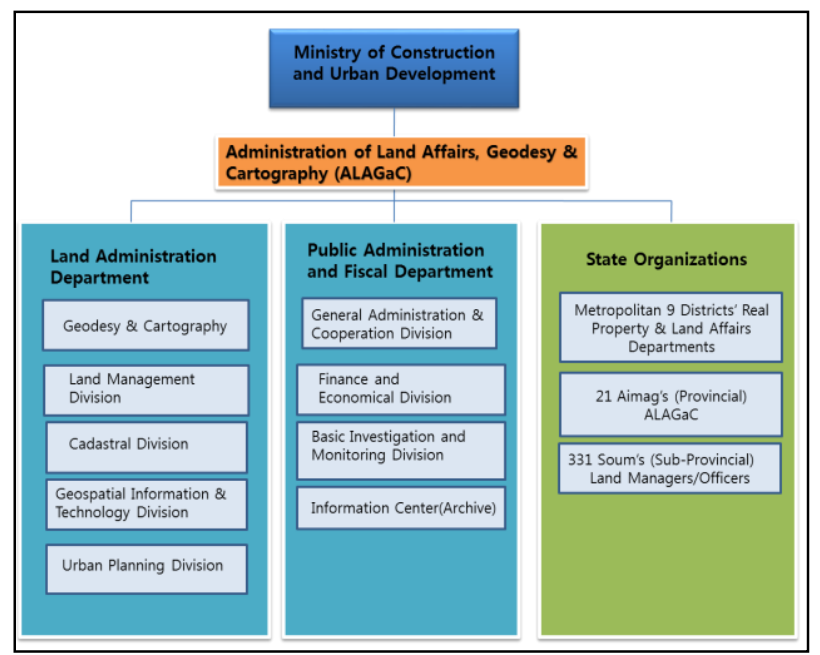

Figure 1. Organizational structure of administration of land affairs, geodesy and cartography (ALAGaC)

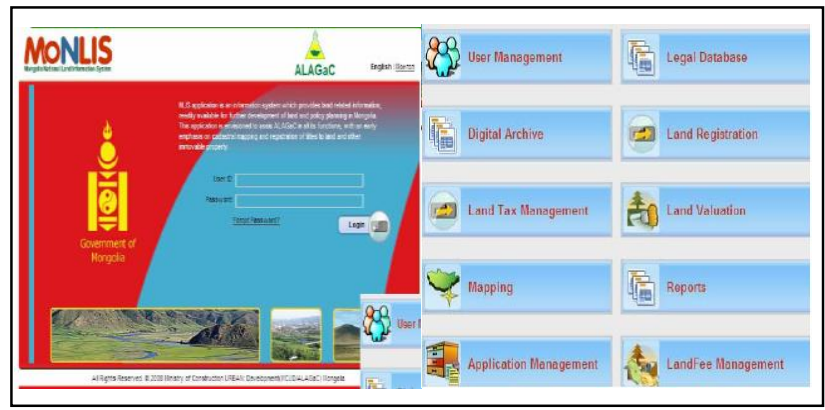

Figure 2. Mongolian NLIS, user-interface and its main functions

In particular, NLIS is to facilitate and support data exchanges between intra-and inter-organizations, efficient cadastral procedures, land registration and taxation, other land related activities, etc. Moreover, it is intended to support business activities related to land, real properties and development of cooperation to other organizations related to ALAGaC in G2B, G2G forms.

\section{CADASTRAL SYSTEM OF MONGOLIA}

According to "Land Cadastre and Cadastral Mapping Law of Mongolia", Cadastre is defined as a comprehensive action of identifying land and other real property's position, boundary, area, volume, quantity, land state and the economic valuation of land quality, imposition of land fee, confirmation of land tenure title in terms of ownership, possession and land use rights. Legal framework for cadastral field provides tenure security, cadastral survey and land registration (all settlement areas, some agriculture areas), multi-purpose cadastre which is for the purpose of property valuation, taxation as well as land market operation, increased public awareness of cadastrial importance, and strengthened human resources in land administration. However, legal framework for cadastral issues is still considered incomplete. Besides legal framework, there are a lot of issues regarding to cadastral developments (e.g. lack of enough support and understanding at the political level, financial difficulties, low budget funding, no data exchange between cadastre and land registry, no comprehensive cadastral updating for all cadastral changes, unreliable cadastral data quality in terms of content and topology, no whole territorial cadastre and lack of coordination between government and donor organizations). Furthermore, there is a challenge of improving existing data quality such as correcting topological errors, cadastral information (e.g. area, boundary) and coordinate conversion in the map, which has been made in different coordinate systems. Existing cadastral law does not include complex procedure for property registration. Cadastral surveying and registration are done separately. It is necessary to produce whole country's land use map and cadastral maps and upgrade unsatisfactory processes of cadastral surveying, mapping, and inadequate registration of land owners, users and possessors.

The current cadastral system is an applicant oriented, duplicated model without any integration (Dashdorj, 2008).

It makes the registration multitude, too costly and time consuming (Figure 3).

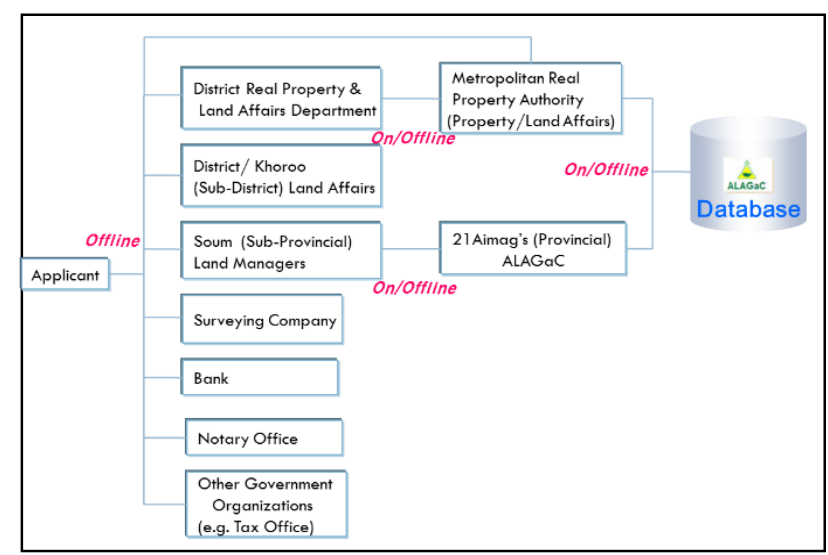

Figure 3. Current institutional structure in cadastral system

In current system, an applicant ought to visit all administrative institutions whether it is public or private. Most cases an applicant has to access to an administrative institution by offline, which denotes an applicant must be in presence. On the whole, it is thoroughly inefficient and need to be changed.

With existing technical potential, the study proposed an improved model with procedural integration and flexibility through unification of current separated system, in broader context with application of e-governance (Figure 4).

Figure 4 illustrates proposed model of institutional connections structure to NLIS in cadastral system of Mongolia. Applicants who have a civil complaint relating to land or land tenure are able to access to applicable institute through internet based network. Applicable state institutions handle directed civil complaints by itself or passing them along an applicable institution through its high-speed intranet network. Civil complaint is resolved at an appropriate institution eventually. On the other hand, in terms of network and current technical issues, connections of NLIS between organizations in Capital city will be based on intranet. It is expected to have connections through intranet all over the country in the future. Moreover, NLIS provide transferring and sharing needed information from and to data communications such as G2C, G2B or G2G through its high-speed reliable connection systems.

Comparing to the current cadastral system (Figure 3), Proposed system is wholly integrated and comprehensive model based on inter/intranet network. Also, from the point of an applicant, system could have a little complexity, however it has much more advantages rather than existing one. To emphasize again it is wholly connected system of administrative institutes that enable 
not only applicants but also administrators' flexible and smooth workflow without mentioning time-consuming, cost-saving and stress-free advantages.

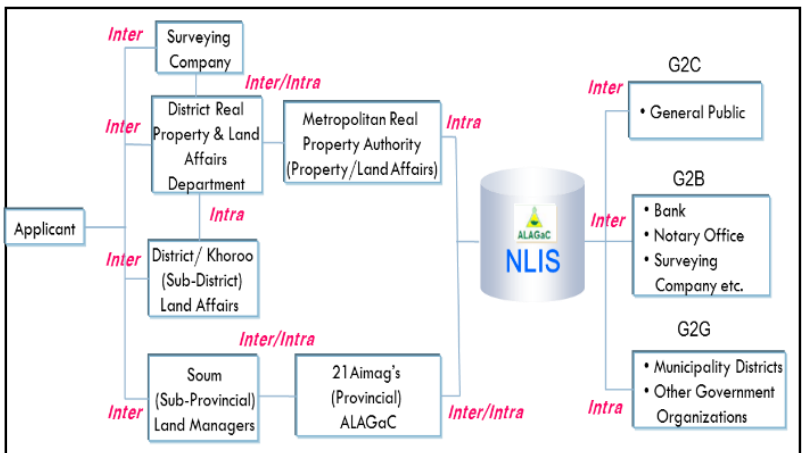

Figure 4. Proposed model of cadastral system in institutional connection with NLIS

Towards full and efficient utilization of NLIS, it is necessary to connect the system to other related state or private organizations in terms of national wholly integration of systems related to cadastral and geographical(Kim). This paper proposed a model for connecting other related institutions except for existing administrational connections plan. In Figure 5, left part(in light blue) is related to administrational while right part is related to extra-state organizations and private surveying companies. In case of state institutions on the right part (in light green), various databases are shown. Those databases generally belong to Mongolian environment database system. Currently this system offer web-based service and statistically approximately 95000 users served per year and about 899254 numbers of data, 3-4 terabyte data is used (Mongolian environmental database system). Besides considering these figures NLIS connections with other database systems will facilitate not only easiness of handling data but also to produce more valued information by amalgamating data through internal system connection within NLIS.

Moreover, from the sustainable economic development perspective, NLIS integration with other related organizations will greatly contribute to the efficiency by cost saving and time consuming. Also, it is expected that the process of duplication i.e. creating geographic information which already exists or collecting information which is already on the other system will be lessened or eliminated. Once the cadastral data (cadastral or legal parcels, properties, parcel identifiers, buildings, legal roads, etc) from administrational organization are integrated within the NLIS, sustainability can be achieved (Enemark, 2012).

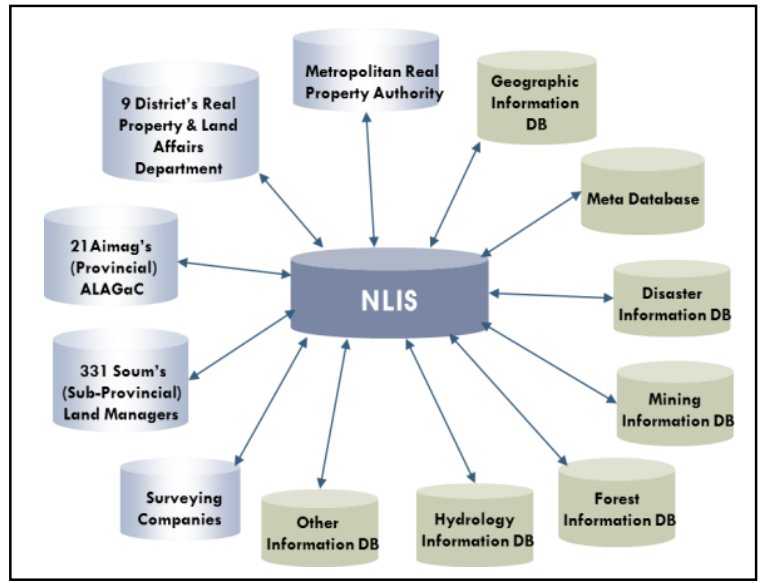

Figure 5. Proposed model of NLIS connection

\section{CONCLUSION AND FUTURE WORK}

This paper proposed two kind of the implementation model for cadastral system development in Mongolia. One is administrational cadastre related procedural structure connection with NLIS, the other one is NLIS connection proposal to the other state or private organizations after its establishment. On the whole, both system will bring tremendous advantages and big changes into the current system. The both proposed system will obviously lead to not only for cadastral system development but also for national development. To implement these proposals, NLIS must be kicked off. If NLIS take effect in reality it will greatly contribute to not only facilitation of duty, and administrational procedurals but also induce sustainable development of national economy through development of hypothec market, revitalization of land and real property, collection of land taxes and fees.

Besides system developments, there are another factors to take into consideration such as good governance and legal environment. In regard to the implementation of proposed model into current cadastral system, there is need to conduct more accurate research with soft and hardware environment, and database management system.

For paper limitations, the paper emitted system internal procedures such as related organizations' data type to be shared and exchanged, also data fusion and its utilizations. Furthermore, for follow-up researches, data components, compatibility and standardization related issues need to be addressed. Also, problems with the system software and hardware should be taken into consideration.

\section{REFERENCES}

Administration of Land Affairs, Geodesy and Cartography, (Figure1), http://www.gazar.gov.mn/ (30 Jul.2015).

Asian Development Bank (ADB), 2012. "Mongolia: Cadastral Survey and Land Registration Project", Validation Report, pp. $1-8$.

Bayarmaa, B., Fiscal Cadastre Project in Mongolia, ALAGaC, (Figure 2)

http://www.csdila.unimelb.edu.au/projects/tehran/Presentations/ pdf/Ppt0000004.pdf.

Dashdorj, E., 2008. Land Cadastre Development in Mongolia, Master's thesis, Munchen Technology University.

Enemark, S., 2012. From Cadastre to Land Governance, FIG Working Week 2012, Young Surveyors Conference.

Enkhzul, B., 2010. A Study on the Characteristic of Mongolian Cadastral System, Master's thesis, Kyungil University.

Mongolian Environmental Database System, http://eic.mn/ (31 Jul. 2015).

Land Cadastre and Cadastral Mapping Law of Mongolia, 1999.

Saandar, M., 2003. Cadastral Survey and Land Registration System Development in Mongolia, TS4 Best Practices in Land Administration, FIG Working Week, Paris, France.

Kim, S., Understanding KLIS, Architecture and Urban Research Information Centre, Ministry of Government Administration \& Home Affairs. 